\title{
How does economic theory explain the Hubbert peak oil model?
}

\author{
Frédéric Reynès ${ }^{\text {a, b, }}$, Samuel Okullo ${ }^{\text {a }}$, Marjan Hofkes ${ }^{\text {a }}$ \\ a Institute for Environmental Studies - Instituut voor Milieuvraagstukken (IVM), Faculty of Earth and Life \\ Sciences (FALW), VU University Amsterdam, De Boelelaan 1085, 1081 HV Amsterdam, The Netherlands \\ b OFCE - Sciences Po Research Centre, 69 Quai d'Orsay, 75007 Paris, France
}

\begin{abstract}
:
The aim of this paper is to provide an economic foundation for bell shaped oil extraction trajectories, consistent with Hubbert's peak oil model. There are several reasons why it is important to get insight into the economic foundations of peak oil. As production decisions are expected to depend on economic factors, a better comprehension of the economic foundations of oil extraction behaviour is fundamental to predict production and price over in the coming years. The investigation made in this paper helps us to get a better understanding of the different mechanisms that may be at work in the case of OPEC and non-OPEC producers. We show that profitability is the main driver behind production plans. Changes in profitability due to divergent trajectories between costs and oil price may give rise to a Hubbert production curve. For this result we do not need to introduce a demand or an exploration effect as is generally assumed in the literature.
\end{abstract}

Keywords: Hubbert peak, Hotelling, shadow price, depletion effect

JEL Classification: Q30, Q41

\footnotetext{
* Corresponding author. Tel.: + 31 (0)20 59 85934. Fax: + 31 (0)20 59 89553. E-mail addresses: frederic.reynes@ivm.vu.nl, samuel.okullo@ivm.vu.nl, marjan.hofkes@ivm.vu.nl.
}

Acknowledgments: The authors acknowledge the financial support of the NWO's ACTS Sustainable Hydrogen research program. 


\section{Introduction}

Calibrating a logistic function on historical oil production data and two estimates of ultimate recoverable reserves, Hubbert $(1956$; 1962) predicted that oil production in the lower 48 US states would peak either in 1965 or in 1970. His 1970 prediction came to pass and Hubbert's methodology to predict oil production subsequently became renowned ${ }^{1}$. Hubbert found that oil production often exhibits a bell shaped extraction trajectory. His model is often defined as a technical approach to oil production because it is supposed to provide a kind of proxy of the technical limit to production.

The accuracy of Hubbert's prediction combined with the relative simplicity of his method had a huge influence on the modelling of oil production in particular among oil peak theorists such as Campbell and Laherrère (1998) and Deffeyes (2001). Nonetheless, the approach has often been criticised both empirically and theoretically ${ }^{2}$. Theoretically, Hubbert's approach has been criticised for lacking economic foundation. The bell-shaped trend followed by production is rather ad hoc. It is not deduced from economic maximisation behaviour and thus does not take into account any economic factors such as prices. From an empirical point of view, the Hubbert model generally fails in predicting production for the Organisation of the Petroleum Exporting Countries (OPEC), whose production has widely diverged from the Hubbert curve since the 1970s (see Rehrl and Friedrich, 2006, p. 2416). This discrepancy casts doubt on the ability of the Hubbert model to accurately predict global oil production in the coming years especially in an era where OPEC will be dominating in terms of reserve and production share ${ }^{3}$.

Economic theory has been able to provide a comprehensive explanation for the divergence of OPEC production from the Hubbert curve. With a non negligible share in the world production (about 30\%), OPEC production has been observed to affect price (see Salant, 1975; 1976; 1982; Hnyilicza and Pindyck, 1976; Pindyck, 1978; Yang, 2008b): a

\footnotetext{
${ }^{1}$ Since then, the Hubbert curve has been applied to modelling depletion of several exhaustible resources such as oil, coal, natural gas and uranium by Hubbert himself (Hubbert, 1956; 1962; 1967) and by other proponents of the Hubbert peaking theory who are reviewed in Section 2.

${ }^{2}$ For an early critic see Ryan (1965). For more recent views see Rehrl \& Friedrich (2006) or Watkins (2006).

${ }^{3}$ In 2007 , OPEC possessed nearly $80 \%$ of the proved reserves for conventional oil (BP, 2008)
} 
coordinated reduction (resp. increase) in production generally leads to a negative (resp. positive) gap between supply and demand, which is reabsorbed by an increase (resp. decrease) in price. OPEC as a cartel has rationally an interest to produce below what the best technology allows since a higher price provides to its members a higher intertemporal profit (i.e. a higher profit during a longer period of time). Consequently, it is common practice to model non-OPEC production via Hubbert curves while modelling OPEC production by solving a profit maximisation program (e.g. Rehrl and Friedrich, 2006).

On the contrary, economic theory has more trouble to justify why the Hubbert curve is exhibited by many non-OPEC producers such as UK North Sea fields, the lower 48 US states or Mexico [for a review of regional Hubbert curves see Brandt (2007)]. In fact, the Hubbert modelling framework could be said to have challenged the basics of neoclassical economic theory on exhaustible resources as influenced by the seminal works of Gray (1914), Fisher (1930) and Hotelling (1931) ${ }^{4}$. According to these neo-classical economic approaches, the optimal level of extraction of a non-renewable resource maximises an intertemporal objective function, in general the profit function in case of an industry or an individual producer, and, alternatively the social welfare function in case of a social planner ${ }^{5}$.

Most of the time, these models do not generate a peak in production but reproduce the famous result of the basic Hotelling model where the resource price rises at the rate of discount and production decreases monotonically via the sensitivity of demand to price. This property was sometimes interpreted as a failure of the neoclassical approach in modelling the oil market. However, several studies have shown that the neoclassical approach is able to generate an oil peak, in particular via changes in cost and/or demand or by introducing an exploration effect (see Uhler, 1976; Pindyck, 1978; Holland, 2008).

The primary aim of this article is to provide economic foundations for bell shaped extraction trajectories. The rationale of economic research on this question is threefold. Firstly, as production decisions are expected to depend on economic factors, the robustness of Hubbert model may, in the future, be strongly affected by the recent important changes in the oil market environment such as the strong increases in demand and price. Secondly, this

\footnotetext{
${ }^{4}$ See Devarajan \& Fisher (1981) for a historical survey.

5 The cases that involve a social utility function are treated in Dasgupta \& Heal (1974), Withagen (1999); Perman et al. (2003, Chap. 15).
} 
investigation may be helpful for understanding the different mechanisms that may be at work in the case of OPEC and non-OPEC producers. Thirdly, a better comprehension of the oil extraction behaviour is fundamental to predict production and price in the coming years where there is a high uncertainty on the capacity of the supply to satisfy the demand.

In this article, we provide a direct economic interpretation to Hubbert peak model that encompasses the technical interpretation. This interpretation seems more realistic than previous attempts to provide economic foundation to Hubbert peak model. Here the Hubbert curve reflects changes in profitability which depends partly on the technical characteristic of the resource via costs. Section 2 discusses the limits of a purely technical approach of the Hubbert model. Section 3 reviews the literature that proposes economic foundations to Hubbert model. Section 4 develops a basic intertemporal economic maximisation model where the resource owner operates in a competitive market, taking prices as given. We show that this model reproduces a Hubbert production curve if the level of profitability follows a bell-shaped curve, for instance by simply assuming that costs follow a U-shaped trajectory. No further assumptions are necessary as is generally the case in previous attempts to provide economic foundations for the Hubbert peak oil model. In particular, there is no need to introduce a demand effect (where demand and thus production increases because cost and thus price decreases) or an exploration effect (where new discoveries allow for a period of increase in production). Moreover, an intertemporal maximisation behaviour is not a fundamental hypothesis either. Indeed, the link between the levels of production and profitability is a fundamental result of economic theory that holds in a static framework that is in the case of a producer who maximises the level of production of a renewable resource.

Section 5 extends the basic model by assuming that the cost of production increases with depletion and shows that it is possible to reproduce a bell curve without assuming a Ushaped cost trajectory. Here intertemporality is fundamental: if the producer expects a period where the discounted marginal cost decreases, her production may increase along with profitability over time until the depletion effect is strong enough to decrease profitability and production. Section 6 discusses the limits of our approach in modelling oil production. Section 7 concludes. 


\section{The technical interpretation of Hubbert model}

Many oil experts and studies interpret the Hubbert model as a technical constraint on oil production. One reason may be that the Hubbert curve matches fairly well the traditional techniques used for the extraction of conventional oil from an oil field: a well is drilled, the downhole pressure pushes up the oil; in order to increase production a second well is drilled, and then a third, a fourth, etc; production hence increases until no more wells can be drilled because the margins of the field are reached and/or the underground pressure becomes too low to push out any more oil, leading to production declines. According to this technical interpretation, which Hubbert himself largely shares ${ }^{6}$, the bell shape would mirror the physical characteristics of the resource (Cleveland and Kaufmann, 1991; Kaufmann, 1991; Kaufmann, 1995; Moroney and Berg, 1999) and the geological factors that influence its extraction (Pesaran and Samiei, 1995) ${ }^{7}$.

This view implicitly assumes that exogenous technical constraints limit production below a level that would be the optimum production (in terms of profit) if there were no technological restriction. A typical example would be the case where the extraction is profitable (because the price is high and costs are low) and where the demand is higher given prices than the technical constraint. The production would then follow the technical limit and would not depend on any economic factors such as prices. In this situation, one might argue that production depends on geophysical constraints and should be modelled as petroleum engineers do. For conventional oil, production capacity may depend on the size and the deepness of the field, the underground pressure and the size of the pipes. For another type of oil, the technical mechanisms that determine extraction trajectories over time are different but for some reasons (that may look mysterious to the economist) Hubbert model appears to give a fairly good approximation of the technical limit to production over

${ }^{6}$ According to Hubbert, production at any particular point in time will be determined by the resources' own physical limits: "[...] although production rates tend to initially increase, physical limits prevent their continuing to do so." (Hubbert, 1956, p. 8).

7 'The basic idea behind Hubbert's model of production (and discovery) is very simple, and is derived from the observation that under the influence of geological factors, there are three distinct phases to the production of an exhaustible resource” (Pesaran and Samiei, 1995, p. 545). 
time. Many economic studies on oil production adopt implicitly this point of view by modelling non-OPEC production as a logistic function (e.g. Kaufmann, 1995; Rehrl and Friedrich, 2006) ${ }^{8}$. If Hubbert logistic model is the most popular approach, numerous variants and extensions sometimes involving economic variables adopt this technical view of oil production (reviewed in Table 1)

\title{
Table 1. Variants and extensions of Hubbert logistic function model
}

\author{
Alternative mathematical functions: asymetric logistic, (a)symetric linear and exponetial curves
}

Brandt (2007) surveys this wide class of models by comparing 139 oil producing regions. He finds that the symmetric Hubbert model provides in average the better fit than alternative mathematical functions.

Multiple Hubbert cycles: As Hubbert model generally gives poor results when applied at a too aggregated level, some studies use multiple Hubbert cycles, that is a Hubbert curve for each petroleum kind (e.g. Rehrl and Friedrich, 2006).

Linking production to reserves: Using US lower 48 states data, Moroney and Berg (1999) assume that production capacity is a function of the size of the proved reserves (a reserve that is exploitable at the current price and technology). As reserves data follows a bell-shaped curve, their model is not that far from the Hubbert one ${ }^{(a)}$.

Linking production to discovery: Laherrère $(2001$; 2003) fits discoveries with a logistic curve and assumes that production follows the discovery trend with a constant time lag. Discovery data may be adjusted for reserve growth or technical improvement in extraction method but these corrections are exogenous and do not depend on the evolution of prices. This is a poor assumption since an increase in price leads to new discoveries via the increase in investment for prospecting and drilling activity and automatically generates new proved reserves (simply because certain oil fields become profitable).

Logistic function and economic variables: Using US lower 48 states data, Kaufmann (1991) and Pesaran and Samiei (1995) find that the gap between the actual production and the logistic curve can be explained by economic and political variables such as the real price or government-mandated capacity constraint. Adding economic variables to the logistic trend surely enriches the model but does not explain why the production follows a logistic trend in the first place.

(a) In Moroney and Berg (1999) model, the production capacity depends also on economic and political variables such as real price or government-mandated capacity constraint.

8 Other studies use the term of "mechanical" instead of "technical" (e.g. Pesaran and Samiei, 1995, p. 551). But the ideas remains the same: the Hubbert model is intepreted as an exogeneous constraint independent of economic factors. 
A purely technical representation of the Hubbert model is unsatisfactory because the level of production is not directly determined by the technical characteristic of the resource but by profitability which depends mainly on three economic factors: the oil price, the extraction costs and the interest rate ${ }^{9}$. Costs reflect the prices of all the inputs entering into the production process such as the intermediary material inputs, labour and capital. The unit cost of the installed production capacity depends (amongst other) on the physical or geological characteristics of the resource. It is higher, the more difficult the extraction in a given oil field. Thus the technical constraints have a direct economic interpretation: they increase the cost of investment and decrease profitability and thus production (for a given oil price). Taking the example of conventional oil, the producer would have to install more wells or use enhanced oil recovery technology if she wishes to stabilise the production when the underground pressure drops. Because of its cost, this additional investment may not be profitable and consequently production decreases.

A technical constraint limits production because the cost of circumventing it is too high. This cost may grow exponentially if the desired level of production is increasingly difficult to reach (e.g. when the resource is nearing depletion). If the desired level of production is impossible to reach because the resource stock is too low, this cost can be viewed as infinite. In oil peak regions, reserves are big enough to allow for an increase in production after the peak. Yet production decreases because the cost of producing one extra unit of oil is too high, that is because the marginal cost (of a higher level of production) is too high. Producing more would lead to a suboptimal profit since the marginal cost would become higher than the oil production price (in the case of a competitive market).

\footnotetext{
${ }^{9}$ The interest rate reflects the trade off the resource owner has to make in choosing to invest in the oil sector with respect to investing in the other sectors. This term could also describe the trade off of choosing to invest today or tomorrow, which is referred to as the discount rate.
} 


\section{The economic interpretation of Hubbert model}

The fact that Hubbert model works remarkably well for most non-OPEC regions is somehow a mystery for the economist since this model does not involve any maximisation strategy from the agent exploiting the resource. The empirical success is no doubt a puzzle for economic theory. Several authors have tried to solve it by proposing an economic foundation for the Hubbert peak model and interpreting peaks in production as the result of an economic maximisation program. They have identified several theoretical situations which lead to a peak in production.

In the first one, the production follows a bell-shaped curve because the production costs follow an U-shaped curve over time. The fact that production increases (resp. decreases) when cost decreases (resp. increases) comes generally from a demand effect: when the price decreases, the demand increases, and so does the production. Several studies follow this reasoning although their modelling strategies or the reasons leading to a U-shaped cost diverge:

Reynolds (1999) reinterprets the Hubbert curve as a cost function that combines the information and depletion effects proposed by Uhler (1976). The information effect reduces costs: the more experience in oil prospecting and extraction, the cheaper the related costs. It reflects a learning curve in oil exploration and exploitation. On the contrary, the depletion effect increases costs: the less oil, the more difficult to find and the more expensive to extract. The author uses an elegant metaphor according to which Robinson Crusoe has to search for a buried resource in order to survive. The probability of success in finding the hidden resource is interpreted as the inverse of the cost function: the higher this probability, the less costly it is to find more of the resource. As this probability increases with the research experience but decreases with the number of discoveries, the model predicts a period of fall in price and then a sudden increase. The price equals the marginal cost which follows a U-curve (more precisely a logistic function) since the depletion effect becomes at some point bigger than the information effect. As a consequence of the adjustment of demand to prices, the production follows a logistic function.

In Reynolds (1999), the marginal cost function is not directly derived from the theoretical model based on probabilities but is assumed to follow an exogenous Hubbert 
curve. This weakness is overcome by Bardi (2005) who specifies explicitly Reynolds probabilistic model and simulates it using Monte Carlo techniques. He shows that the model reproduces a bell-shaped production curve whose symmetry depends on the main hypothesis of the model: such as the taking into account or not of technical changes.

Holland (2008, Model 2) brings a related argument within a standard neoclassical approach of exhaustible resources where the producer maximises her intertemporal profit. Similarly to the previous information effect, the technological change has a decreasing effect on cost and thus price. But the increase in price comes from a increase in the scarcity rent (i.e. the shadow price) and not directly from costs. The result is the same: the peak arises when the scarcity effect offsets the technical change effect.

The same authors propose other models based on intertemporal maximisation that reproduce also a peak. Holland (2008, Model 1) assumes that price increases with the scarcity rent. Via the demand function this leads to an endogeneous decrease in demand. In the case of an exogeneous increase in demand (due for instance to the increase of the standard of living of the population), production increases as long as the exogeneous increase in demand is higher that the endogeneous decrease in demand. At a certain point in time, "the demand increase will eventually be less than the full marginal cost increase, and equilibrium production will decrease" (Holland, 2008, p.65). Holland (2008, Model 4) proposes also a site development model where the peak is driven by an increase in production capacity due to the production at newly developed sites, the decrease in production still resulting from a decrease in demand (that follows the increase in price due to the increase in scarcity).

Holland's Model 3 is based on Pindyck (1978) who assumes that the cost of production increases as the reserve base depletes and that new discoveries depend positively on the exploratory effort and negativelly on the cumulative discovery. This model shows a different production pattern depending on the size of the initial reserve. If the initial reserve is large, the production (resp. the price) decrease (resp. increase) monotoneously as in the basic Hotteling model. But if the initial reserve is low, "price will start high, fall as rerserves increases (as a result of exploratory activity), and then rise slowly as reserves decline" (Pindyck, 1978, p. 11). Production is close to a Hubbert model with a possible asymetry in the bell-shaped curve. 


\section{An intertemporal model reproducing Hubbert via cost}

Previous attempts to provide economic foundation to Hubbert peak oil model often rely on a demand effect to explain the decrease in production after the peak: the increase in cost causes the increase in price which causes the decrease in demand and thus in production. Unfortunately, this theoretical explanation is not supported by the empirical facts. The producers who experienced a decrease in production in the past were not constrained by the demand: despites the oil price increases, demand never stopped increasing because of the increases in the world population and in its standard of living. Consequently, the decrease in production comes more likely from the producers' rational choice than from an external demand constraint. In this section and in the following one, we provide economic foundations for this argument by developing a model where a competitive producer chooses her level of production such as that she maximises her intertemporal profit. This model shows that Hubbert production curve may arise from changes in profitability due to divergent trajectories between costs and the oil price. We believe that the profitability argument is more realistic that the demand effect proposed by previous authors.

Let us suppose that the oil producer takes price as given (since she operates in a competitive market and therefore does not affect price) and faces the following technology, cost and profit functions:

$$
\begin{array}{ll}
Y_{t}=\left(I_{t}^{\text {nput }}\right)^{\theta} & \text { with } \theta>0 \\
C_{t}=P_{t}^{\text {Input }} I_{t}^{\text {nput }}=P_{t}^{\text {Input }} Y_{t}^{\theta^{-1}} & \\
\Pi_{t}=P_{t} Y_{t}-C_{t}=P_{t} Y_{t}-P_{t}^{\text {Input }} Y_{t}^{\theta^{-1}} &
\end{array}
$$

Where $Y$ is the quantity of oil produced (or the extraction level), $P$ is the oil price (or the output price), $C$ the cost of production, and $t$ is the time operator ${ }^{10} . I^{\text {phut }}$ is an index of all the possible input quantities used in the production process (labour, capital, energy, etc.). Consequently, the input price index $\left(P^{\operatorname{Inpht}}\right)$ is a function of the prices of these inputs. If it depends on the oil price, the algebraic resolution of the maximisation program is more arduous. One way to circumvent this complication is to consider that $Y$ is the net production

\footnotetext{
${ }^{10}$ Variables in growth rate are referred to as $\dot{X}_{t}=X_{t} / X_{t-1}-1$ and all coefficients are positive.
} 
that is the quantity of oil actually extracted minus the quantity of oil used as an input. This way, the oil price is excluded from the input price index and does not intervene as a cost in the profit function ${ }^{11}$.

In order to have general results, we do not assume any particular function for the input index such as a Constant Elasticity of Substitution (CES), Cobb-Douglas or Translog function. In other words, we do not impose any constraint on the elasticity of substitution between production factors. The only constraint is that the production function is homogeneous of degree $\theta$ which corresponds to the level of returns to scale: if $\theta<1$ (resp. $=1,>1$ ), there is decreasing (resp. constant, increasing) returns to scale. In case of increasing (resp. decreasing) returns to scale, a 1\%-increase in the production factors generates more (resp. less) than 1\%-increase in the production.

The producer determines the optimal production trajectory by maximising its intertemporal profit subject to the constraint (s.t.) of a limited resource stock ${ }^{12}$ :

$$
\underset{Y_{t}}{\operatorname{Max}} \sum_{t=1}^{n} \Pi_{t} /(1+\rho)^{t} \text { s.t. } \sum_{t=1}^{n} Y_{t} \leq R_{0}^{e s}
$$

Where $R_{t}^{e s}$ is the size of the reserve (or the resource stock) at the instant $t$, and $\rho$ the discount factor.

\footnotetext{
${ }^{11}$ Note, however, that in our particular case of perfect competition, the optimal production resulting from the maximisation program presented below would be unchanged if we assumed that the input price index was a function of the oil price: because prices are taken as given, their first derivative with respect to production is zero.

${ }^{12}$ In order to ease the resolution, we assume further that the profit at each period is non-negative $\left(\Pi_{t} \geq 0\right)$. This means that (1) the price is high enough to cover the average cost and that (2) the production is never negative $\left(Y_{t} \geq 0\right)$ because the producer is assumed not to buy oil in order to store it and sell it at a more profitable period.
} 


\subsection{Analytical solution}

Following the Karush-Kuhn-Tucker approach, we introduce the slack variable $v=\sqrt{\mathrm{R}_{n}^{e s}}$ in order to rewrite this maximisation program under inequality constraint as a maximisation program under equality constraint ${ }^{13}$. Applying the Karush-Kuhn-Tucker theorem the Lagrangian to this model problem is:

$$
L=\sum_{t=1}^{n} \Pi_{t} /(1+\rho)^{t}+\lambda\left(\mathrm{R}_{0}^{e s}-v^{2}-\sum_{t=1}^{n} Y_{t}\right)
$$

As the Lagrange multiplier $\lambda$ is unique and constant over time in this simple model, its time subscript $t$ is dropped. The optimum must satisfy the following necessary first order conditions:

$$
\begin{aligned}
\partial L / \partial Y_{t}= & \Leftrightarrow \Leftrightarrow \lambda(1+\rho)^{t}=\partial \Pi_{t} / \partial Y_{t}=P_{t}-C^{\prime}\left(Y_{t}\right)=P_{t}-\theta^{-1} P_{t}^{I n p u t} Y_{t}^{\left(\theta^{-1}-1\right)} \\
& \partial L / \partial \lambda=0 \Leftrightarrow R_{0}^{e s}-v^{2}-\sum_{t=1}^{n} Y_{t}=0 \\
& \partial L / \partial v=0 \Leftrightarrow 2 \lambda v=0
\end{aligned}
$$

These conditions are sufficient for optimality if the objective function $\left(\Pi_{t}\right)$ is a continuously differentiable strictly convex function. This is only the case for decreasing returns to scale $(\theta<1)$. In case of constant or increasing returns to scale $(\theta \geq 1)$, it is possible to increase indefinitely the profit by increasing the level of production. If there were no stock limit, the optimal production would be infinite. By increasing indefinitely production, price would be affected at some stage. This violates the hypothesis where producers take price as given because their production is too small to affect price. This is the well-known result according to which perfect competition is only possible if we assume decreasing returns to scale technology $(\theta<1)$.

If there is a stock limit and constant or increasing returns to scale optimum $(\theta \geq 1)$, the optimum of the maximisation program [4] is not defined by the set of equations [6] to [8].

\footnotetext{
13 See for instance Dixit (1990, Chap. 3), Simon \& Blume (1994, Chap. 18 \& 19) or Yang (2008a, Chap. 7) for more details on the resolution of nonlinear optimisation problems under inequality constraint.
} 
Instead, it is characterised by several solutions or by one "corner" solution where the producer exhausts her full resource. In case of constant returns to scale $(\theta=1)$, the average cost of production is constant. As a consequence, there is infinity of possible optima if the prices of input and output both grow at the same rate as the discount factor. There is one "corner" solution if the prices of input and output do not grow at the same rate as the discount factor: the producer exhausts all her resource at the last (resp. first) period if the growth rate of prices of input and output is higher (resp. lower) than the discount factor because it is (resp. not) more profitable to wait. Increasing returns to scale $(\theta>1)$ is always characterised by one corner solution because the average cost of production decreases when production increases. It is thus more profitable to produce everything at one period. The choice of the optimum period will depend on the trajectories of prices and on the discount factor.

As the cases of constant or increasing returns to scale are more relevant in an imperfect competition framework where production plans affect the price, we shall assume from now on decreasing returns to scale $(\theta<1)$. In this case, the first order necessary conditions [6], [7] and [8] are sufficient for optimality and solving the maximisation program with inequality constraint is equivalent to comparing two optima (because of condition [8]):

\section{- $\quad$ The optimum where the inequality constraint is inactive: $\lambda=0$ and $v \neq 0\left(\Leftrightarrow R_{n}^{e s} \neq 0\right)$}

This optimum is equivalent to maximising the profit without constraint that is to maximising profit in every period. Condition [6] becomes identical to the first order condition in case of a competitive producer of a conventional (renewable) commodity: price equal marginal cost. The optimum does not depend on the discount factor and the level of production depends positively on the ratio between the price of output and the price of the input:

$$
Y_{t}=\left(\theta P_{t} / P_{t}^{I n p u t}\right)^{1 /\left(\theta^{-1}-1\right)}
$$

An increase in the output price or a decrease in the input price leads to an increase in production. This result is not surprising since the ratio between the oil and the input prices $\left(P_{t} / P_{t}^{\text {Input }}\right)$ is an indicator of the profitability of the firm. This ratio is in fact the "real" oil price faced by the producer since the deflator considered by the latter is the input price. 
When the real oil price increases, the producer's revenue $\left(P_{t} Y_{t}\right)$ increases more than its costs (Equation [2]). The producer has thus an incentive to increase its production.

Combining [9] and [7] allows for the calculation of the reserve stock at the end of the maximising period. If $R_{n}^{e s}>0$, we can conclude that the initial reserve is large enough to be not constraining over the maximisation period. In other words, the decreasing returns to scale hypothesis acts as a cost constraint that is more constraining than the stock constraint. If $R_{n}^{e s}<0$, the initial stock is not large enough and the producer cannot reach the unconstrained optimum. Of course this case always arises if the time horizon is large enough. We must then look at the optimum where the inequality constraint is active.

- The optimum where the inequality constraint is active: $\lambda \neq 0$ and $v=0\left(\Leftrightarrow R_{n}^{e s}=0\right)$

In this case, the producer cannot produce as much as she wishes every period because of the stock limit. The optimal production is thus lower than the one defined at [9]:

$$
Y_{t}=\left(\theta \frac{P_{t}-\lambda(1+\rho)^{t}}{P_{t}^{\text {Input }}}\right)^{1 /\left(\theta^{-1}-1\right)}
$$

Assuming input and output price stability, the optimal production decreases over time if the discount factor is above 0 because future profit is considered less important relatively to the present profit. However, if the prices of the input and the output are growing at the rate of discount (i.e. $P_{t}=P_{0}(1+\rho)^{t}$ and $\left.P_{t}^{\text {Input }}=P_{0}^{\text {Input }}(1+\rho)^{t}\right)$, the optimal level of extraction does not depend on the value of the discount rate and is constant up to the point where the final exhaustion of the resource occurs. Under these assumptions, production is stable over time because the discounted marginal profit $\lambda$ is stable over time. This result is a consequence of the so-called "Hotelling rule". As Hotelling (1931) assumes no extraction costs, the original Hotelling rule states that at the optimum the price of a non-renewable resource should grow at the same rate as the discount factor in order to maximize the present value of the resource 
capital over the extraction period ${ }^{14}$. As the price is negatively related to the aggregate level of production via the demand function, the basic Hotelling model expects the optimal level of production to decrease steadily over time (all other things being equal). Taking production costs into consideration, the Hotelling rule becomes the first necessary condition [6] which states that the optimum level of extraction is such that the marginal profit $(\partial \Pi / \partial Y)$ grows at the rate of discount. Unlike the original Hotelling rule, condition [6] can be satisfied when the oil price does not increase at the rate of discount. For instance, if the oil price is constant and if the marginal cost decreases at the rate of discount, the marginal profit $(\partial \Pi / \partial Y)$ grows at the rate of discount. Consequenly, unlike the basic Hotelling model, the optimum level of production is not necessary decreasing over time when one accounts for production costs. This more general framework allows variety of extraction trajectories that depends on the trajectories followed by the input and oil prices.

Moreover Equation [10] shows that the level of production is lower, the lower the value of $\lambda$. From Equation [6], we see that $\lambda$ is the discounted (or present) value of the marginal profit (at the optimum level of production) and is stable across time in this simple model. From a mathematical point of view, this parameter is the Lagrange multiplier. It measures how much profit increases if production increases by relaxing the constraint (that is by increasing the initial reserve). From an economic point of view, $\lambda$ can be interpreted as the maximum price a producer is willing to pay for acquiring one extra unit of the resource. It is sometimes viewed as a kind of rent for the producer because it implies that the price is above marginal cost (Equation [6]). Alternatively, it could be seen as a kind of extra cost reflecting the loss in profit compared to a situation where the producer would have an unlimited resource. For these reasons, $\lambda$ takes on several names in the economic literature: (the discounted value of) the shadow price the resource, the scarcity rent, the opportunity cost, the economic rent or the user cost.

Combining [10] and [7], we show that $\lambda$ is a negative function of the initial reserve $\left(R_{0}^{e s}\right)$, i.e. the higher the initial reserve, the closer the solution is to the unconstrained optimum and

\footnotetext{
14 Assuming a discount factor $\gamma$, Hotelling (1931, p. 140) gives the following justification: "Since it is a matter of indifference to the owner of a mine whether he receives for a unit of his product a price $p_{0}$ now or a price $p_{0} . e^{p t}$ after time $t$, it is not unreasonable to expect that the price $p$ will be a function of the time of the form $p=p_{0} . e^{p t}$. $[\ldots]$ The various units of the mineral are then to be thought of as being at any time all equally valuable $[\ldots]$ ".
} 
the smaller is the shadow price (because the opportunity of profit increases become smaller). The limit case of $\lambda=0$ arises when the initial reserve is high enough to allow the producer to reach the unconstrained optimum. This is the previous case where the constraint is inactive and some petrol is left at the end of the maximisation period.

The close link between the size of the initial reserve and $\lambda$ may be more comprehensively understood by considering the static case of one single maximisation period $(n=1)$. Figure 1 depicts the evolution of profit (as defined in Equation [3]) when production increases. Although the values chosen for the calibration are arbitrary and not fundamental in terms of interpretation, we set values that replicate the situation of the competitive producer in the real world. This may give a better intuition of the economic reasoning. The oil price is set at 100 US dollar $(\$)$ and the input price at $\$ 10$. As a direct consequence of the decreasing returns to scale hypothesis $(\theta=0.5<1)$, profit increases until the optimal level of production, 5 millions of barrels ( $\mathrm{mn}$ bbls) ( $\mathrm{C}$ in Figure 1), and then decreases. If the producer could produce as much as she wanted, she would produce 5 . At this point, the tangent to the profit curve (the marginal profit) is zero $\left(\lambda^{C}=\partial \Pi / \partial Y=100-20 \times 5=0\right)$ as stated by the first order condition [6]. Moreover, the average cost of production $\left(C / Y=P^{\text {Input }} Y=10 * 5\right)$ is $\$ 50$.

If the initial reserve is $1 \mathrm{mn}$ bbls, the producer cannot reach the unconstrained optimal production level, and produces 1 which is the constrained optimal production level ( $\mathrm{A}$ in Figure 1). The marginal profit at the constrained optimum (the parameter $\lambda$ ) is positive and equal to 80. Increasing the size of the resource stock, let us say to 3 (B in Figure 1), decreases the value of $\lambda$ to 40 . The closer to the unconstrained optimum (C), the flatter the tangent to the profit curve since at that point $\lambda=0 . \lambda$ is higher at $A$ than at $\mathrm{B}$ because $\mathrm{A}$ is further from the unconstrained optimum C. Hence the producer will gain more from an increase of reserve at A that at $\mathrm{B}$. At $\mathrm{C}, \lambda=0$ because the producer cannot increase its profit by increasing its production. Although the graphic representation may not be possible anymore, the interpretation of the value of the shadow price remains the same with a higher number of periods $(n>1)$. 
Figure 1. Link between the shadow price and the initial reserve

Profit (П)

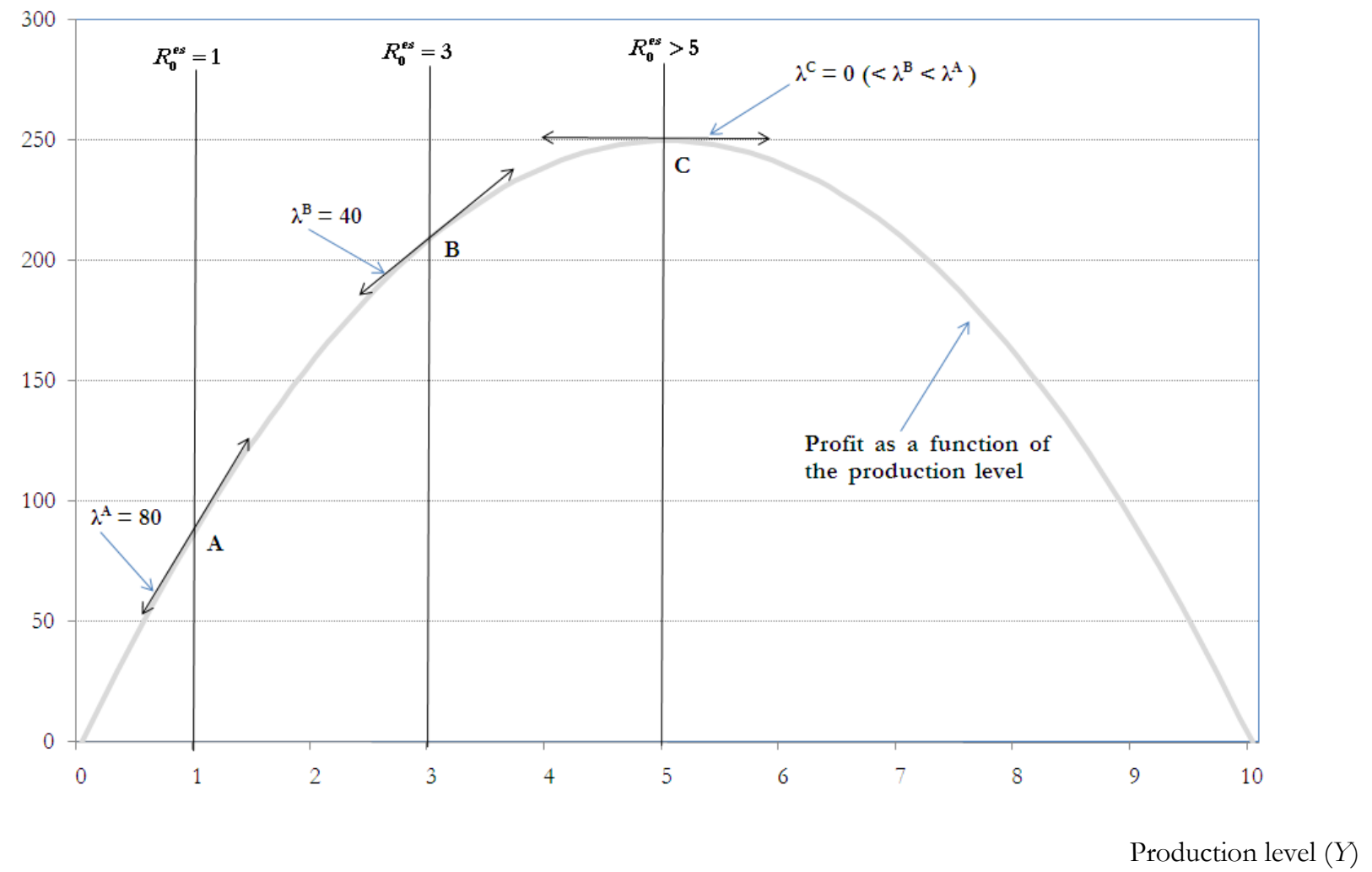

Key: The profit function is Equation [3] with $P=100, P^{I n p u t}=10$ and $\theta=0.5$, that is $\Pi=100 Y-10 Y^{2}$. Thus the shadow price (marginal profit) is $\lambda=\partial \Pi / \partial Y=100-20 Y$; authors' calculation.

From Equation [6], we see also that $\lambda$ is a positive (resp. negative) function of the oil price (resp. the input price). The economic interpretation is similar to the one about the link between the initial reserve and the shadow price: the lower the oil price (or the higher the input price), the lower the profitability, the lower the optimal level of production, the closer the constraint to the unconstrained optimum and thus the lower the shadow price $\lambda$.

Here as well, the production evolves according to profitability. But the indicator of profitability is not the same as when the resource constraint is inactive. Instead of being simply the real oil price $\left(P_{t} / P_{t}^{I n p u t}\right)$, the indicator of profitability is the gap between the real 
oil price and the real shadow price $\left(\lambda(1+\rho)^{t} / P_{t}^{\text {Input }}\right)$. As shown in Equation [10], production increases when the real oil price increases faster than the real shadow price.

\subsection{Numerical simulations}

Although the systems [6], [7] (and [8] with $\lambda \neq 0$ and $v=0$ ) constitutes a system of $n+1$ equations with $n+1$ unknowns $\left(Y_{t} ; \lambda\right)$, it cannot be easily solved analytically because of strong non-linearity. The model is linear only if we assume a specific level of returns to scale: $\theta=0.5$. Even in that case, the explicit analytical solution is arduous to find, leading to very complicated formulas for each of the endogenous variables $\left(Y_{t} ; \lambda\right)$ in terms of the exogenous variables. As this does not bring much insight for the problem we are studying here, we look now at numerical solutions. In this article, all the simulations were performed with the GAMS program ${ }^{15}$.

First, consider the case in which both input and output prices are growing at the rate of discount (i.e. $P_{t}=P_{0}(1+\rho)^{t}$ and $\left.P_{t}^{\text {Input }}=P_{0}^{\text {Input }}(1+\rho)^{t}\right)$. We know from the discussions above that $Y_{t}$ will be constant for each period and that $\lambda$ is higher, the lower the quantities of the initial resource stock and the lower the input price. Table 2 provides an illustration of this link assuming that the number of periods is $n=200$, level of the returns to scale is $\theta=0.5$ and the initial oil price is $P_{0}=\$ 100$. The discount rate is set at $\rho=0.05$, although, changing the value of the discount rate does not have any impact on the numerical simulation: production does not depend on the discount rate when the input and output prices are growing at the rate of discount (see Equation [10]).

But changing the initial reserve stock or the initial input price will affect the level of extraction as the four similations of Table 2 show. In the first three simulations, the initial input price is fixed at $\$ 10$, whereas the initial oil reserves stock takes decreasing values: 1000 , 850 and $750 \mathrm{mn}$ bbls. In the fourth case, the initial reserves are kept at the level of case 3 (750 $\mathrm{mn}$ bbls), whereas the initial input price drop to $\$ 5$.

\footnotetext{
15 The scripts used are available upon request.
} 
The values chosen for the exogenous variables present an extraction pattern close to the case of a competitive producer that could be observed in the real world. The world proved reserve of crude oil was 1213 billion barrels (bbls) in 2007 (OPEC, 2008, Table 33) whereas the level of 2008 world crude oil production was 73.8 million (mn) bbls per day (EIA, 2009, Table 11.1b). In case (1) of Table 2, the initial reserves are set to $1000 \mathrm{mn}$ bbls and the resulting level of production is $5 \mathrm{mn}$ bbls annually (i.e. $0.014 \mathrm{mn}$ bbls per day) until depletion occurs at the horizon of the simulation. This simulation corresponds to an oil producer that would possess in the real world $0.08 \%$ of the total proved reserve and extract nearly $0.02 \%$ of the total production. This producer can be considered taking the oil price as given because the level of production is too small to affect prices ${ }^{16}$.

In this first simulation, the resource depletion constraint is found to be inactive, i.e. the shadow price is null $(\lambda=0)$; this implies that the producer receives no scarcity rent and will therefore extract as though the resource were non-exhaustible. The producer will not increase production in the event of an increase in initial reserve level ( $\lambda$ can not be negative) and any additional reserves would remain un-extracted at the end of the time horizon. Moreover the optimal production $Y_{t}$ is such that the resource constraint is just inactive. Consequently depletion occurs but only in the last period. Case 1 is nothing else but case $\mathrm{C}$ in Figure 1 in the situation of multiple periods. The level of extraction is constant because the initial input price is the same and because all prices grows at the rate of discount.

The resource constraint becomes active if we increase the simulation horizon or if we decrease the initial reserves. The latter is simulated in Cases 2 and 3 in Table 2. With smaller initial reserves of 850 and $750 \mathrm{mn}$ bbls of oil, the shadow value of the resource $\lambda$ jumps from 0 to 15 and 25 respectively because a smaller resource stock prevents the producer from maintaining extraction at the level of Case 1 over the selected time horizon (200 periods). As a consequence, production $\left(Y_{t}\right)$ has to drop or alternatively extraction has to take place over a shorter period. As we do not change the time horizon, annual production falls instead.

\footnotetext{
16 The fact the producer will extract her reserve over 200 years may be seen unrealistic: in the real world, the lifetime of a field is approximately 30 years whereas the world ratio between reserve and production is close to 40 years (BP, 2008). A more realistic figure in this respect can easily be obtained by changing the time unit: assuming that the time unit is 2 months, the extraction lasts 33 years. With $0.11 \%$ of the total production, this is still the case of a competitive producer.
} 
This fall in production can be viewed as a loss in revenues for which the producer asks compensation through an increase in the scarcity rent $\lambda$. Without this increase, the first order condition [6] would be violated and the solution would not be optimal. Making the initial reserves even smaller increases the shadow price $\lambda$ even more (Case 3). This is an illustration of the economic principle that the scarcer a resource, the higher the rate of return asked by the producers because they cannot exploit indefinitely their resource.

Table 2. Effect on the shadow price of changes in reserves and input price

\begin{tabular}{|c|c|c|c|c|}
\hline & \multicolumn{4}{|c|}{ Cases } \\
\hline & (1) & (2) & (3) & (4) \\
\hline \multicolumn{5}{|l|}{ Results } \\
\hline Shadow price: $\lambda$ & 0 & 15 & 25 & 62.5 \\
\hline Production: $Y_{t}$ & 5 & 4.25 & 3.75 & 3.75 \\
\hline \multicolumn{5}{|l|}{ Assumptions } \\
\hline Initial reserve: $R_{0}^{e s}$ & 1000 & 850 & 750 & 750 \\
\hline Initial input price: $P_{0}^{\text {Input }}$ & 10 & 10 & 10 & 5 \\
\hline \multicolumn{5}{|c|}{$\begin{array}{l}\text { Key: numerical simulation of Equation [4] with } \dot{P}_{t}=\dot{P}_{t}^{\text {Input }}=\rho=0.05, n=200, P_{0}=100 \text { and } \theta=0.5 \text {; } \\
\text { production and reserve expressed in } \mathrm{mn} \text { bbls and prices in \$; authors' calculation. }\end{array}$} \\
\hline \multicolumn{5}{|c|}{ Let us suppose now that the initial input price decreases from $\$ 10$ (Case 3 in Table 2) to } \\
\hline \multirow{2}{*}{\multicolumn{5}{|c|}{$\begin{array}{l}\$ 5 \text { (Case } 4 \text { in Table 2) keeping the initial reserves of Case } 3 \text { ( } 750 \mathrm{mn} \text { bbls of oil). The } \\
\text { discounted shadow value is observed to increase from } 25 \text { to } 62.5 \text { whereas the level of } \\
\text { production remains unchanged. A decrease in the input price corresponds to an increase in } \\
\text { profitability. If the resource were un-exhaustible, the producer would increase its production }\end{array}$}} \\
\hline & & & & \\
\hline \multicolumn{5}{|c|}{$\begin{array}{l}\text { as we can see from Equation [9]. As the limited size of the reserve does not allow it, the } \\
\text { stability in production is compensated with an increase in the scarcity rent } \lambda \text {. This is the only }\end{array}$} \\
\hline \multirow{2}{*}{\multicolumn{5}{|c|}{$\begin{array}{l}\text { way for shadow value } \lambda \text { plus the marginal cost to equate to the output price, that is for the } \\
\text { first order condition [6] to remain satisfied. An increase in the initial oil price }\left(P_{0}\right) \text { would give }\end{array}$}} \\
\hline & & & & \\
\hline \multicolumn{5}{|c|}{ a similar result whereas an increase of the initial input price $\left(P_{0}^{I n p u t}\right)$ would logically have the } \\
\hline opposite effect. & & & & \\
\hline
\end{tabular}


Because both input and output prices grow at the rate of discount, the optimal level of extraction chosen by the producer is constant over time irrespectivelly of the size of reserves. This is true both for the unconstrained and constrained optima (Equations [9]) and [10]). This result comes from the Hotelling rule and from the fact that the profitability is stable over time. In contrast, when output and input prices are growing at different rates, producers may shift production from one period to another in response to how the discounted net profits evolve.

In particular, it can be readily observed from Equations [9] (the unconstrained optimum) and [10] (the constrained optimum) that our simple model is capable of reproducing Hubbert model via costs: if the price of the inputs follows a U trajectory (via for instance the interaction between information and depletion effects), the production will follow a bell shaped curve. This happens without having to introduce a demand effect as in Reynolds (1999), Bardi (2005) and Holland (2008) or an exploration effect as in Pindyck (1978). Here Hubbert peak model arises out of changes in profitability due to a U trajectory followed by the input prices, rather than because of the physical characteristics of the resource. An graphic illustration is given in Figure 2 in the case of the unconstrained optimum (Equation [9]). The oil price is assumed constant while the input price follows $\mathrm{U}$ trajectory based on a simple quadratic function. As the input price falls, production increases up to the point where it reaches a maximum where costs are at their minimum (the $100^{\text {th }}$ period). Then the input price starts to raise forcing production to decline. Because the quadratic function is symmetric, the extraction pattern is also symmetric. If the path for the input price was not symmetric, but still U-shaped, the trajectory for extraction would become non-symmetric but still bell-shaped. More generally, if the ratio between the output and input prices (i.e. the real oil price) follows a bell shaped curve, production will follow a Hubbert curve.

Although intertemporal maximisation is not a fundamental assumption to reproduce a Hubbert peak model, it seems more realistic in the case of non-renewable resources because it is more rational to take into account the stock constraint. The fact that Hubbert peak model can be reproduced in a static maximisation framework (the unconstrained model Equation [9]) is nonetheless interesting in at least two respects. Firstly, it shows that the link between the levels of production and profitability is a general result of economic rationality. Secondly, one may argue that some oil producers have actually a very short intertemporal 
horizon for several reasons: for example, (1) if the producer is highly uncertain about the future and thinks that at any moment new technologies will come up and lead to a drop in demand for his resource; (2) due to political pressure, some oil country producers have to achieve a minimum revenue. In these cases, the producer may behave as one of a renewable resource: by maximising only its current profit, she sets her production according to her cost constraint but not according to her resource stock constraint (embodied here in the shadow price).

Figure 2: Peak in production when the input price exhibits a U-shaped trajectory.

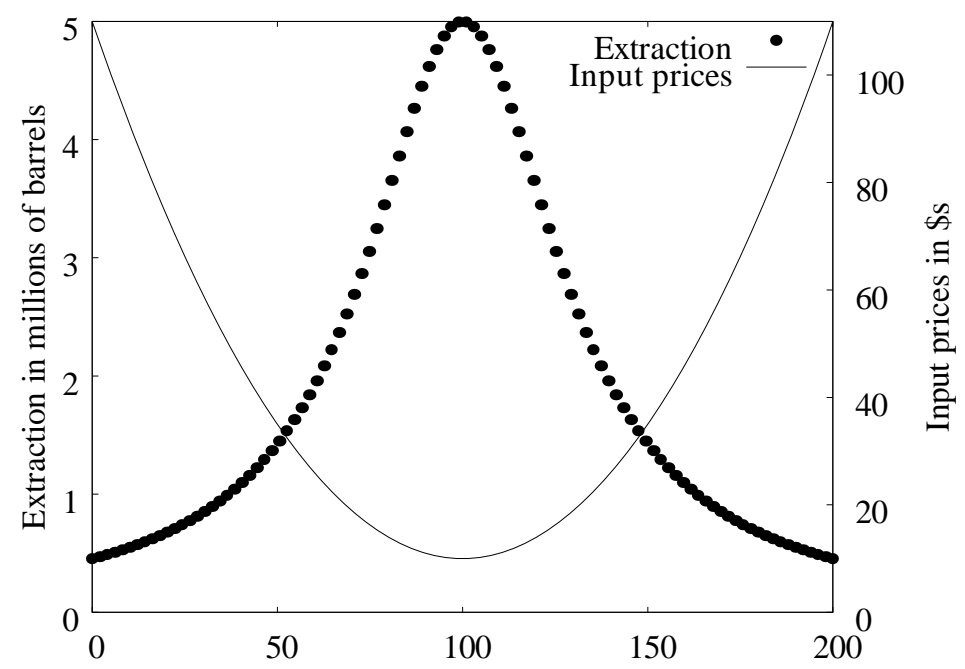

Key: simulation of Equation [9] with $P_{t}^{\text {Input }}=\frac{(t-100)^{2}}{100}, n=200, P_{0}=100, \theta=0.5$; authors' calculation.

\section{Introducing stock depletion effects in costs}

Noteworthy are the two shortcomings of the simple model discussed above. First, it does not reproduce the Hubbert production curve endogeneously but only via specific exogeneous trajectories for prices. Second, the shadow price is constant over time because the profit function [3] does not depend on the resource stock. Increasing the initial resources stock therefore affects uniformally profit across time. Assuming that cost depends on the stock via a depletion effect, we show both analytically and numerically that these two 
shortcomings can be removed. A common way to do this is to assume that the price of input is a negative function of the reserve (e.g. as in Holland, 2008) ${ }^{17}$ :

$$
P_{t}^{\text {Input }}=\bar{P}_{t}^{\text {Input }}\left(\mathrm{R}_{t-1}^{e s}\right)^{-\alpha} \quad \text { with } \alpha \geq 0
$$

Where $\bar{P}^{\text {Input }}$ is the exogenous component of the input price referred to from now on as the exogenous input price. $\alpha$ is the elasticity of costs to reserves.

For the algebraic resolution, it is convenient to reformulate the maximisation program [4] and the Lagrangian [5] as follows:

$$
\begin{aligned}
& \underset{Y_{t} ; R_{t}^{e s}}{\operatorname{Max}} \sum_{t=1}^{n} \Pi_{t} /(1+\rho)^{t} \text { s.t. }\left\{\begin{array}{l}
\mathrm{R}_{t}^{e s}=\mathrm{R}_{t-1}^{e s}-Y_{t} \\
\mathrm{R}_{n}^{e s} \geq 0
\end{array}\right. \\
& L=\sum_{t=1}^{n}\left[\Pi_{t} /(1+\rho)^{t}-\lambda_{t}\left(\mathrm{R}_{t}^{e s}-\mathrm{R}_{t-1}^{e s}+Y_{t}\right)\right]-\lambda_{n}\left(\mathrm{R}_{n}^{e s}-v^{2}\right)
\end{aligned}
$$

The necessary and sufficient conditions for optimality are:

$$
\begin{aligned}
\partial L / \partial Y_{t}=0 \Leftrightarrow & \lambda_{t}(1+\rho)^{t}=P_{t}-C^{\prime}\left(Y_{t}\right) \Leftrightarrow Y_{t}=\left(\theta \frac{P_{t}-\lambda_{t}(1+\rho)^{t}}{\bar{P}_{t}^{I \text { Input }}}\left(R_{t-1}^{e s}\right)^{\alpha}\right)^{1 /\left(\theta^{-1}-1\right)} \\
& \partial L / \partial \lambda_{t}=0 \Leftrightarrow R_{t}^{e s}-R_{t-1}^{e s}+Y_{t}=0 \\
& \partial L / \partial R_{t}^{e s}=0 \Leftrightarrow \lambda_{t}-\lambda_{t-1}=-\alpha \frac{\bar{P}_{t}^{\text {Input }}}{(1+\rho)^{t}} Y_{t}^{\theta^{-1}}\left(R_{t-1}^{e s}\right)^{-\alpha-1} \\
& \partial L / \partial v=0 \Leftrightarrow 2 \lambda_{n} v=0
\end{aligned}
$$

This model presents strong similarities with the one of Section 4. Condition [14] which determines the optimal level of production is similar to Equation [10] except that $\lambda$ is not constant anymore (and thus has a time subscript) and that the optimal level of production is positively related to the resource stock. Equation [15] is nothing else but a reformulation of $[7]^{18}$. Moreover we can see that the previous model correspond to the case of $\alpha=0$ which implies that $\lambda$ is constant (Equation [16]) and that the optimal level of production is independent of the resource stock (Equation [14]).

\footnotetext{
17 This link between the input price and the size of the reserve is determined by geophysical and engineering aspects.

${ }^{18}$ Indeed summing conditions [15] one to another for all $t$ collapses into [7] since $v^{2}=\mathrm{R}_{n}^{e s}$.
} 
If $\alpha>0, \lambda$ decreases over time. Increasing the initial resources stock does not affect uniformally profit across time anymore. Such an increase now generates more gain at the beginning than at the end of the maximisation period. In other words, the oil producer has more incentive to find new reserves at the start of extraction. Assuming that the output price and the exogenous input price grow at the rate of discount (i.e. $P_{t}=P_{0}(1+\rho)^{t}$ and $\left.\bar{P}_{t}^{\text {Input }}=\bar{P}_{0}^{\text {Input }}(1+\rho)^{t}\right)$, the evolution of the optimal production depends on the dynamic of the reserve and of the discounted shadow price $\lambda$ (Equation [14]). As the resource stock decreases over time, production decreases over time. This result has a direct economic explanation. Because of the depletion effect, the input price increases and thus the profitability and the optimal level of production decreases over time. Since profitability is lower at the end of the maximisation period, increasing the initial resource stock generates less (discounted) profit than at the begining of the sample. Consequently the discounted marginal profit $(\lambda)$ decreases over time (as stated by the optimal condition [16]) but this decrease is too slow to offset the depletion effect and increase production. This result is simulated in Figure 3 where in addition a strong correlation between production (see panel (ii)) and the discounted net profit (see panel (i)) appears.

It is notable from the figure that unlike the model presented in Section 4, output and the discounted shadow price are not constant anymore: they decrease over time. The discounted marginal cost on the other hand increases over time at an increasing rate (see panel (i) of Figure 3) because of the depletion effect. Consequently, as less and less of the resource remains, it becomes increasingly expensive and less profitable to extract. As evidenced in panel (ii) of Figure 3, this results into a steady fall in production.

Figure 3. Trajectories when prices grow at the rate of discount
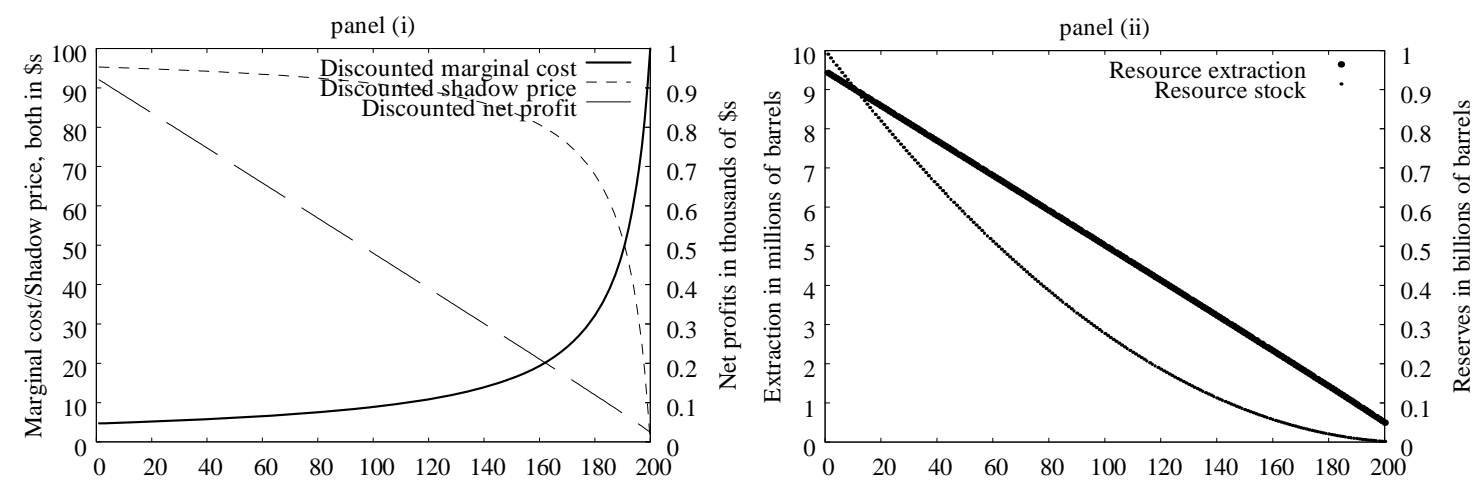
Key: simulation of Model [12] with $\dot{P}_{t}=\dot{\bar{P}}_{t}^{\text {Input }}=\rho=0.05, n=200, P_{0}=100, P_{0}^{\text {Input }}=250, R_{0}^{e s}=1000$, $R_{n}^{e s}=1.978, Y_{n}=0.591, \theta=0.5, \alpha=1$, and $\Phi=0$; authors' calculation.

If we relax the assumption that the output and exogenous input prices grow at the discount rate, the extraction rate may not decrease as steadily as observed in Figure 3 (where the output and input prices grow at the same rate). When prices (both output and exogenous input prices) grow at the same rate, which is smaller than the discount rate $\left(\dot{P}_{t}=\dot{\bar{P}}_{t}^{\text {Input }}<\rho\right)$, production still decreases through the combination of two effects that decrease profitability. This first is the depletion effect that increases the input price and decreases production (via the decrease in the ratio $\left(R_{t-1}^{e s}\right)^{\alpha} / \bar{P}_{t}^{\text {Input }}$ in Equation [14]). The second is the decrease at the beginning in the gap between the actual and shadow oil prices $\left(P_{t}-\lambda_{t}(1+\rho)^{t}\right)$ because the oil price grows at a smaller rate than the discount rate $\left(\dot{P}_{t}<\rho\right)$. At the end of extraction however, the discounted shadow price $(\lambda)$ is small enough for the gap between the actual and shadow oil price to increase. This has a positive effect on production but too small compared to the depletion effect to lead to an increase in production. Moreover, the fall in production is non linear at an increasing rate: as the present value of the oil price decreases while the input price increases through the depletion effect, the producer has a tendency to shift the most production to the first period.

Consider now the case where the growth rate of the output price is higher than that of exogenous input prices, but lower than the discount rate $\left(\dot{\bar{P}}_{t}^{\text {Input }}<\dot{P}_{t}<\rho\right)$. Equation [14] shows that production may increase over time for some periods depending on the dynamic of the gap between the actual and shadow oil price (which is nothing else but the marginal cost): $P_{t}-\lambda_{t}(1+\rho)^{t}=(1+\rho)^{t}\left(P_{0}\left(1+\dot{P}_{t}\right)^{t} /(1+\rho)^{t}-\lambda_{t}\right)$. Indeed, we see that this gap increases when the (discounted) oil price, $P_{0}\left(1+\dot{P}_{t}\right)^{t} /(1+\rho)^{t}$, is higher than the (discounted) shadow price $\lambda$. This has an increasing effect on production that may offset the depletion effect. Consequently, 3 scenarios for oil production could be observed (1) production decreases, (2) production increases and then decreases, (3) production increases monotonically.

The first scenario (decreasing production) is reproduced in Figure 4 by assuming that the initial exogenous input price $\bar{P}_{0}^{\text {Input }}=\$ 500$. In addition, we assume that the exogenous 
input price is time invariant $\left(\dot{\bar{P}}_{t}^{\text {Input }}=0\right)$ and that the growth rate of the oil price is lower than the discount rate i.e. $\dot{P}_{t}=0.04$ and $\rho=0.05$.

With those hypotheses, production decreases over time, although it is relatively stable during the first ten periods before it starts falling at more or less exponential rates. It is also noticeable that the discounted net profit exhibits the same shape as the production curve (see panel (i)). Production falls slowly in the initial periods because the discounted oil price is higher than the discounted shadow price. This acts as a driving force that increases production. This force is not strong enough to offset the depletion effect but limits for some time the decrease in production.

\section{Figure 4. Decreasing production curve with depletion effect}
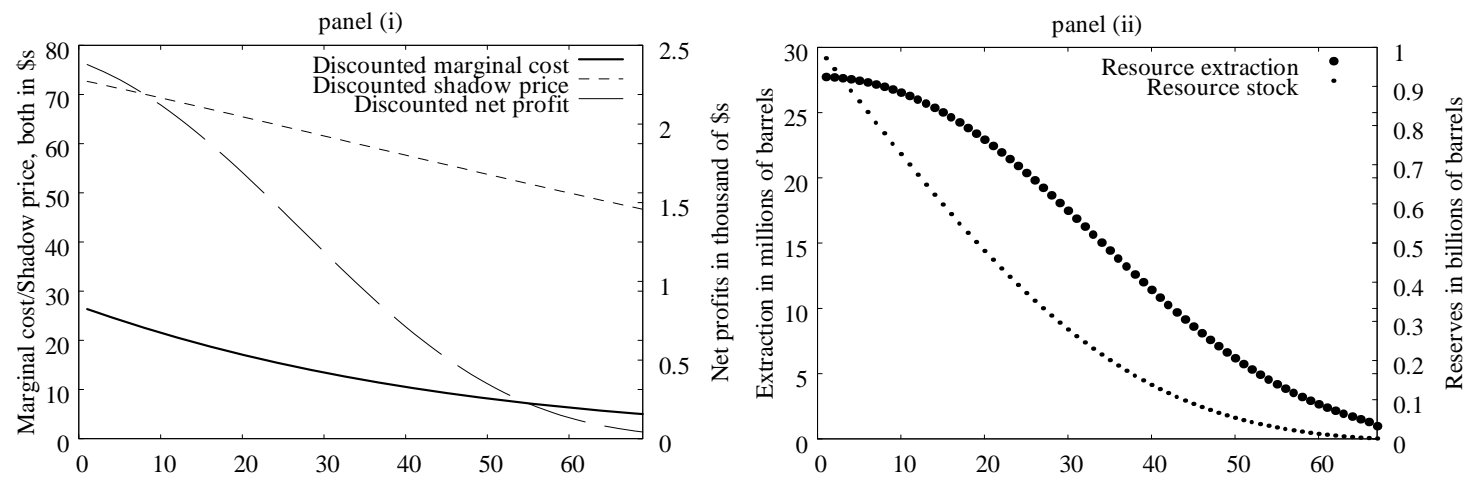

Key: simulation of Model [12] with $\dot{P}_{t}=0.04, \dot{\bar{P}}_{t}^{\text {Input }}=0, \rho=0.05, n=200, P_{0}=100, \bar{P}_{0}^{\text {Ipput }}=500$, $R_{0}^{e s}=1000, P_{0}^{\text {Ihpht }}=0.5, R_{n}^{e s}=2.7 * 10^{-7}, \theta=0.5, \alpha=1$, and $\Phi=0$; authors' calculation.

If the oil price is sufficiently higher than the shadow price, production may increase for a certain period of time. This can be done here by increasing the initial input price as we have shown previously the negative correlation between the input price and the shadow price (see Table 2): the higher the input price, the less profitable the extraction, the less gain from an increase in production, the lower the shadow price. Multiplying the initial exogenous input price $\left(\bar{P}_{0}^{\text {Input }}\right)$ by 100 compared to the previous case, the initial input price (computed from [11]) jumps from $\$ 0.5$ to $\$ 50$ and the initial shadow price drops from $\$ 72$ to \$32. All other parameters remain the same as those in Figure 4. Extraction in panel (ii) Figure 5 rises from initially low levels (about $0.7 \mathrm{mn}$ bbls) reaches a peak at about $11 \mathrm{mn}$ 
bbls in the $117^{\text {th }}$ period and then steeply declines to zero in the $195^{\text {th }}$ when the resource is physically exhausted. Here as well, the discounted net profit mirrors exactly production by following bell-shaped curve (see panel (i)).

Here, the exogenous initial input price is substantially high leading to initially high marginal costs with low profitability and thus low production. However, the discounted input price initially decreases over time, which reflects into the sharp decline of the discounted marginal costs. This leads to an increase in profitability and thus in production. Because the growth rate of the oil price is lower than the discount rate, the gap between discounted oil price and the discounted shadow price (the discounted marginal cost in panel (i) of Figure 5) decreases. This leads to smaller and smaller increase in production until the depletion effect, due to increasingly lower stock levels, becomes stronger. At this point profitability, and hence production, peak and start to decline.

Note that the Hubbert curve in Figure 5 is generated by simply making the gap between oil price and the shadow price (i.e. the marginal costs) substantially high in the initial periods. No period of decreasing cost is introduced as previously proposed in the literature via the information effect or the technological change effect. Here the key element reproducing a Hubbert curve is that the oil price grows at a lower rate than the rate of discount so that the gap between the discounted oil price and the discounted shadow price (i.e. the discounted marginal costs) decreases for a certain period of time. This allows for extraction to be less profitable in the initial periods and incites the producer to delay extraction.

\section{Figure 5. Hubbert production curve with depletion effect}
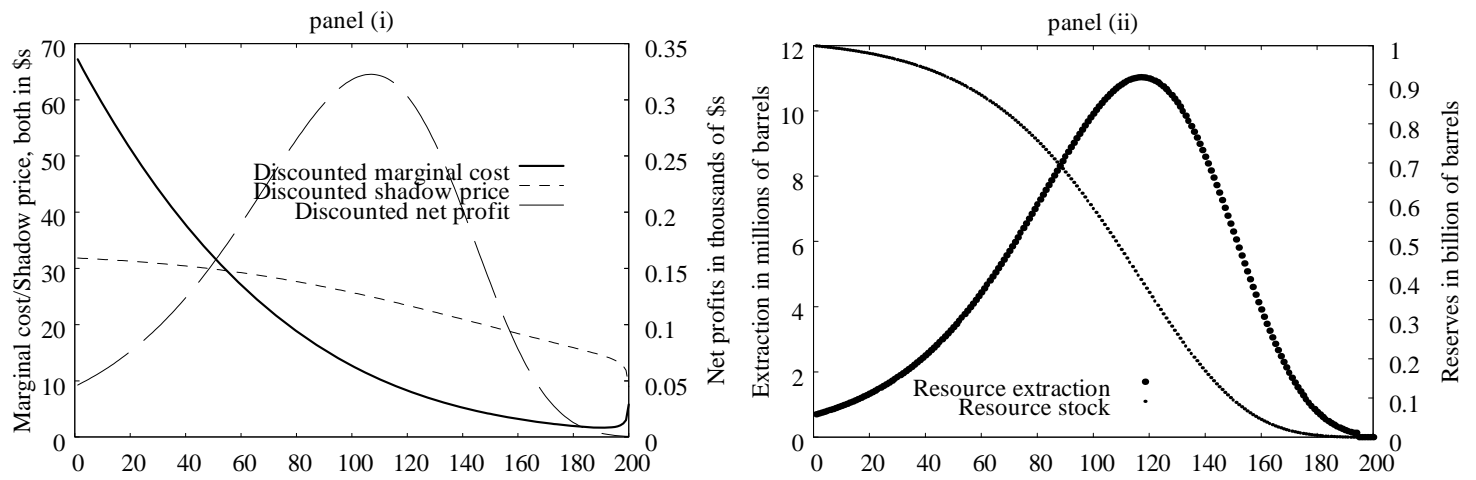

Key: simulation of Model [12] with $\dot{P}_{t}=0.04, \dot{\bar{P}}_{t}^{\text {Input }}=0, \rho=0.05, n=200, P_{0}=100, \bar{P}_{0}^{\text {Ihput }}=50000$, $R_{0}^{e s}=1000, R_{n}^{e s}=8.3 * 10^{-7}, R_{0}^{e s}=1000, \theta=0.5, \alpha=1$, and $\Phi=0$; authors' calculation. 
A fourth sub-scenario is not presented here since we find it trivial. It corresponds to the case where extraction increases monotonically. This scenario is actually a special case of the scenario in Figure 5 with the phase of decreasing production truncated before it occurs. If the optimisation period was sufficiently extended, it would be possible to observe the decreasing production phase as well.

As a conclusion, the last two sections have shown that production could exhibit a Hubbert curve depending on the dynamics of the oil price and costs. Higher profitability at the start (resp. middle, end) of the mining period leads to more extraction in the initial (resp. middle, last) periods. In this respect, the close correlation between the discounted net profit and production exhibited in Figure 3 to Figure 5 is quite striking. Moreover our investigations show that the Hubbert curve is just one of the many trajectories a production path could follow. They provide evidence for the thesis that profitability, reflected here by the trajectory of the discounted net profit, is important in determining whether a Hubbert curve is reproduced.

\section{Limits to the approach and possible extensions}

The two previous sections have identified several conditions that generate the Hubbert peak model in the case of a small competitive producer. The evolution of costs and more generally of profitability appeared to be a key element to provide an economic foundation to a peak in oil production. We shall however recognise that the analytical framework retained is rather restrictive since we only looked at the case of a competitive producer facing no uncertainty about the future and a simple cost function. We made this choice for mainly two reasons.

Firstly, at first approximation, the case of a small competitive producer seems quite realistic for most non-OPEC producers since their production is small enough not to influence the oil price. Although in the reality, the future is not perfectly known, the production plans depend on anticipation of prices and cost. The simple model presented here can be viewed as providing the optimal extraction pattern based on these anticipations. Anticipations on the oil price depend on anticipations on aggregate demand and the other 
producers' supply whereas anticipations on costs depend mainly on anticipations on technical changes and the depletion effect.

Secondly, this simple framework allows showing easily the impact of profitability in production decisions. However, this link remains in any more general framework that assumes that the producer sets her production plan in order to maximise her profit. Under this hypothesis, the incentive to increase (or decrease) the level of production comes from the expected increase (decrease) in benefit of doing so. Except in countries where production decisions are purely based on political discretionary measures, oil producers choose their level of production according to economic factors. A more complex model will certainly change the determinants of profitability but not the fact that profitability is the main driver of production plans.

For instance, the case of imperfect competition would modify the first order condition [6] as follows:

$$
\partial L / \partial Y_{t}=0 \Leftrightarrow \lambda(1+\rho)^{t}=P_{t}\left(1+\eta_{t}^{-1}\right)-C^{\prime}\left(Y_{t}\right)
$$

Because the price is now affected by the production level, the level of production will depend also on the elasticity of the demand (addressed to the producer) with respect to the price: $\eta_{t}=\frac{\partial Y_{t}}{\partial P_{t}} \frac{P_{t}}{Y_{t}}$. Assuming a specific demand function, this more realistic model with several producers would also have the advantage to determine endogenously the price level. But this is a more arduous optimisation problem since several objectives have to be maximised simultaneously. This can be dealt with using iterative non linear programming (e.g. Salant, 1982) or mixed complementary approaches (e.g. Yang, 2008). This increase in complexity would not change the main argument presented here: oil production trajectories and thus the eventuality of a Hubbert peak is primary the reflection of changes in profitability.

Our study suggests that further research, investigating how the link between profitability and production behaves when the model is extended to reflect more realistically the actual functioning of the oil market, may prove promising. In addition to the case of imperfect competition, other possible extensions are taking into account of the uncertainty on demand, of prospection activity and of a more general cost function. It would also be more realistic to distinguish between investment plans and production plans. The former determines the 
optimum level of production capacity to be installed whereas the latter determines the optimum level of production under the constraints of a fixed production capacity for a certain period of time. Once again, this would make the model more realistic but this would not change our main conclusion: changes in the level of extraction chosen by an oil producer reflect primary changes she faces in profitability.

\section{Conclusion}

The aim of the paper was to provide economic mechanisms leading to oil supply curves consistent with Hubbert oil peak model. We find that there are two main ways to reproduce a Hubbert peak via costs: (1) as already proposed in the literature, production follows a bellshaped curve when costs are assumed to follow a U-shaped curve. One important difference with the literature is that our result does not come from the effect of costs on demand via the oil price. It comes from the effect of costs on profitability, which seems to be more realistic regarding empirical facts and has the advantage to encompass the purely technical interpretation of Hubbert model. Because of the hypothesis of decreasing returns to scale, a decrease (increase) in cost increases (decreases) profitability and thus production. This result is quite general in the sense that it holds in the absence of intertemporal constraints (that is if the oil production did not have any quantitative limit). It can thus be reproduced in a static framework in which the producer sets the level of production by maximising its profit without constraint on the level of production. (2) The second way only assumes that cost increases over time due to a depletion effect by relating negatively costs to reserve. It does not need a period where costs decrease but is reproduced in an intertemporal framework. When the discounted marginal cost decreases over time, profitability and thus production may increase until a peak where the depletion effect is high enough to decrease profitability and thus production. 


\section{References}

Bardi, U., 2005. The mineral economy: a model for the shape of oil production curves. Energy Policy 33 (1), 53-61.

BP, 2008. Statistical Review of World Energy. www.bp.com. Available at http:/ / www.bp.com/productlanding.do? categoryId=6929\&contentId=7044622.

Brandt, A. R., 2007. Testing Hubbert. Energy Policy 35 (5), 3074-3088.

Campbell, C. J., Laherrère, J. H., 1998. The end of cheap oil. Scientific American 278 (6).

Cleveland, C. J., Kaufmann, R. K., 1991. Forecasting Ultimate Oil Recovery and Its Rate of Production: Incorporating Economic Forces into the Models of M. King Hubbert. The Energy Journal 12 (2), 17-47.

Dasgupta, P., Heal, G., 1974. The Optimal Depletion of Exhaustible Resources. The Review of Economic Studies 41, 3-28.

Deffeyes, K. S., 2001. Hubbert's Peak: The Impending World Oil. Princeton: Princeton University Press.

Devarajan, S., Fisher, A. C., 1981. Hotelling's "Economics of Exhaustible Resources": Fifty Years Later. Journal of Economic Literature 19 (1), 65-73.

Dixit, A. K., 1990. Optimization in Economic Theory. (2nd ed.) Oxford: Oxford University Press.

EIA, 2009. Monthly Energy Review. Energy Information Administration. Available at http://www.eia.doe.gov/emeu/mer/inter.html.

Fisher, I., 1930. The theory of Interest. New York: Macmillan.

Gray, L. C., 1914. Rent Under the Assumption of Exhaustibility. The Quarterly Journal of Economics 28 (3), 466-489.

Hnyilicza, E., Pindyck, R. S., 1976. Pricing policies for a two-part exhaustible resource cartel: The case of OPEC. European Economic Review 8 (2), 139-154.

Holland, S. P., 2008. Modeling Peak Oil. The Energy Journal 29 (2), 61-79.

Hotelling, H., 1931. The Economics of Exhaustible Resources. The Journal of Political Economy 39 (2), 137-175.

Hubbert, M. K., 1956. Nuclear Energy and Fossil Fuels. Drilling and production practice 23, $7-$ 25.

Hubbert, M. K., 1962. Energy Resources. Council, National Research. 
Hubbert, M. K., 1967. Degree of Advancement of Petroluem Exploration in the United States. In A.A.of Petroluem Geologists (Ed.), American Association of Petroluem Geologists (Bulletin 511) (pp. 2207-2227).

Kaufmann, R. K., 1991. Oil production in the lower 48 states : Reconciling curve fitting and econometric models. Resources and Energy 13 (1), 111-127.

Kaufmann, R. K., 1995. A model of the world oil market for project LINK Integrating economics, geology and politics. Economic Modelling 12 (2), 165-178.

Laherrère, J., 2001. Forecasting future production from past discoveries. www.hubbertpeak.com. Available at http://www.hubbertpeak.com/laherrere/opec2001.pdf.

Laherrère, J., 2003. Future of oil supplies. www.oilcrisis.com. Available at http://www.oilcrisis.com/laherrere/zurich.pdf.

Moroney, J. R., Berg, M. D., 1999. An integrated model of oil production. The Energy Journal $20(1), 105$.

OPEC, 2008. Annual Statistical Bulletin 2007. Organization of the Petroleum Exporting Countries. Available at http://www.opec.org/library/Annual\%20Statistical\%20Bulletin/ASB2007.htm.

Perman, R., Ma, Y., McGilvray, J., Common, M., 2003. Natural Resource and Environmental Economics. (3rd ed.) Addison Wesley.

Pesaran, M. H., Samiei, H., 1995. Forecasting ultimate resource recovery. International Journal of Forecasting 11 (4), 543-555.

Pindyck, R. S., 1978. The Optimal Exploration and Production of Nonrenewable Resources. The Journal of Political Economy 86 (5), 841-861.

Rehrl, T., Friedrich, R., 2006. Modelling long-term oil price and extraction with a Hubbert approach: The LOPEX model. Energy Policy 34 (15), 2413-2428.

Reynolds, D. B., 1999. The mineral economy: how prices and costs can falsely signal decreasing scarcity. Ecological Economics 31 (1), 155-166.

Ryan, J. M., 1965. Discussion. Bulletin of the American Association of Petroleum Geologists 49 (10), 1713-1727.

Salant, S. W., 1975. Nash-Cournot equilibrium for an exhaustible resource like oil. International Finance Discussion Papers 63, Board of Governors of the Federal Reserve System. Available at http://www.federalreserve.gov/pubs/ifdp/1975/63/ifdp63.pdf.

Salant, S. W., 1976. Exhaustible Resources and Industrial Structure: A Nash-Cournot Approach to the World Oil Market. Journal of Political Economy 84 (5), 1079-1093. 
Salant, S. W., 1982. Imperfect competition in the international energy market: a computerized Nash-Cournot model. MPRA Paper 12021, University Library of Munich. Available at http://mpra.ub.uni-muenchen.de/12021/.

Simon, C. P., Blume, L. E., 1994. Mathematics for Economists. W W Norton.

Uhler, R. S., 1976. Costs and Supply in Petroleum Exploration: The Case of Alberta. The Canadian Journal of Economics / Revue canadienne d'Economique 9 (1), 72-90.

Watkins, G. C., 2006. Oil scarcity: What have the past three decades revealed? Energy Policy 34 (5), 508-514.

Withagen, C., 1999. Optimal extraction of non-renewable resources. In J.v.Bergh (Ed.), Handbook of Environmental and Resource Economics (pp. 49-58). Edward Elgar Publishing.

Yang, X.-S., 2008a. Introduction to Mathematical Optimization: From Linear Programming to Metaheuristics. Cambridge International Science Publishing.

Yang, Z., 2008b. How Does ANWR Exploration Affect OPEC Behavior? --A Simulation Study of an Open-loop Cournot-Nash Game. Energy Economics 30 (2), 321-332. 